\title{
Analytical Study of Mechanism of Concrete Cracking and Its Propagation Due to Corrosion of Reinforcement in RCC
}

\author{
A. M. Jadhav', H. K. Munot ${ }^{2}$ \\ ${ }^{1} \mathrm{M}$. Tech Structure, College of Engineering Pune, Pune, India \\ ${ }^{2}$ Department of Civil Engineering, College of Engineering Pune, Pune, India \\ Email: ajit.jadhav811@gmail.com,hkm.civil@coep.ac.in
}

Received 15 February 2016; accepted 27 March 2016; published 30 March 2016

Copyright (C) 2016 by authors and Scientific Research Publishing Inc.

This work is licensed under the Creative Commons Attribution International License (CC BY). http://creativecommons.org/licenses/by/4.0/

(c) (7) Open Access

\begin{abstract}
The experimental results which were carried out by different researchers on corrosion of RCC beam were validated in ABAQUS. A finite element (FE) model similar to experimental condition was generated in ABAQUS. The model with different percentages of corrosion and with varying load conditions was also generated. The deflections of RCC beam for different corrosion percentages and for varying load conditions were then validated. The model is then used to explore the effects of bar radial expansion, due to formation of corrosion products, on the cracking of cover concrete. The predictions are compared with tests results from reinforced concrete accelerated corrosion specimens. The aim of the analytical investigation was to reveal the mechanism for the development of concrete cracking due to corrosion of reinforcement. Further the finite element model will be used to explain qualitatively the experimentally determined relationship between amount of corrosion for concrete cracking and ratio of concrete cover to bar diameter, as well as that between reinforcement bond strength and amount of corrosion.
\end{abstract}

\section{Keywords}

Corrosion of Reinforcement, Cracking of Concrete, Finite Element, ABAQUS

\section{Introduction}

Reinforced concrete has been used as essential materials in main load-carrying system of various structures in several countries. Reinforced concrete is recognized to be durable and capable of withstanding a variety of environment conditions. Nevertheless, failures of structures still do occur as a result of premature steel reinforce- 
ment corrosion. The corrosion of rebar in reinforced concrete deteriorates the strength of a structure by reducing its load carrying capacity.

Corrosion is the process of the transformation of a metal to its "native" form, which is the natural ore state, often as oxides, chlorides or sulphates. This transformation occurs because the compounds such as the oxides "involve" less energy than pure metals, and hence they are more stable thermodynamically. The corrosion process does not take place directly but rather as a series of electrochemical reactions with the passage of an electric current. Corrosion also depends on the type and nature of the metal, the immediate environment, temperature and other related factors. The corrosion may be defined as "the destructive attack of a metal by chemical or electrochemical reaction with its environment”.

Steel in concrete is normally immune from corrosion because of the high alkalinity of the concrete; the $\mathrm{pH}$ of the pore water is found to be more than 12.5, which protects the embedded steel against corrosion. This alkalinity of concrete causes passivation of the embedded reinforcing bars. A microscopic oxide layer, which is the "passive" film, forms on the steel surface due to the high $\mathrm{pH}$, which prevents the dissolution of iron. Furthermore, the concretes made using low water-cement ratios and good curing practices have a low permeability, which minimizes the penetration of the corrosion inducing ingredients. In addition, low permeability is believed to increase the electrical resistivity of the concrete to some degree which helps in reducing the rate of corrosion by retarding the flow of electrical currents within the concrete that accompany the electrochemical corrosion process.

Consequently, corrosion of the embedded steel requires the breakdown of its passivity. However, as the global warming becomes worse along with the increase of $\mathrm{CO}_{2}$ content in air, carbonation may break down the passive layer. Those structures in the tidal zone, or roads and bridge decks suffering from de-icing salt can also have the passive layer broken down due to the chloride attack. Without the passive layer, the steel is subjected to water and air and so initiation and further the propagation of corrosion of steel bar happen. Hsu and Hsu (1994) performed work to find out complete stress-strain behaviour of high-strength concrete under compression [1]. Nayal and Rasheed (2006) proposed tension stiffening model for concrete beams reinforced with steel and FRP bars [2]. Lubliner et al. (1989) worked on constitutive model based on an internal variable-formulation of plasticity theory for the non-linear analysis of concrete. Onset and amount of cracking were studied by a simple post processing of the finite-element plasticity solution [3]. Castel et al. (2000) studied mechanical behavior of corroded reinforced concrete beams [4]. Azher and Syed (2005) carried out work on a prediction model for the residual flexural strength of corroded reinforced concrete beam [5]. Ballim et al. (2003) studied corrosion in reinforcement and found out deflection of RC beams using an experimental critique of current test methods [6]. Broomfield and John (1997) worked on corrosion of steel in concrete with thorough investigation and repair strategies [7]. Cabrera et al. (2001) showed the effect of reinforcement corrosion on the strength of the steel and concrete bond [8]. Li and Zheng (2005) performed work to study propagation of reinforcement corrosion in concrete and its effects on structural deterioration [9]. Coronelli and Gambarova (2004) did structural assessment of corroded reinforced concrete beams [10]. Eyre and Nokhasteh (1992) investigated strength assessment of corrosion damaged reinforced slabs and beams [11]. Fin et al. (2008) showed the effect of under-reinforcement on the flexural strength of corroded beams [12]. Patil (2011) conducted work on residual flexural strength of RC beams subjected to corrosion [13].

The present study involves the modeling of reinforced concrete beam specimens with varying percentages of corrosion $(0 \%, 2.5 \%, 5 \%, 7.5 \%, 10 \%)$ and subjected to different load conditions in ABAQUS. Corrosion has been initiated in the model in terms of rust layer around the tensile steel in the required part. The specimens were then modeled and tested. Later the results were validated with the available data. The results from these tests are used to study the changes in flexural behavior of corroded reinforced concrete (RC) beams with increasing level of corrosion process.

\section{Experimental Work}

Many researchers have carried out the experimental work on effect of progressive corrosion on flexural strength of RC beams. The experimental work carried out by Mr. Ajit Patil in College of Engineering Pune [13] is used for comparison of the analytical results. In this literature a number of RC beams are casted and corrosion has been initiated and propagated by impressing a direct current to the tensile steel. The specimens were then tested at various levels of corrosion. These beams are then tested to study the changes in flexural behaviour of corroded reinforced concrete (RC) beams with increasing level corrosion. 


\section{Material Property}

\section{1) Steel}

Deformed steel bars of $10 \mathrm{~mm}$ in diameter and $900 \mathrm{~mm}$ in length are used for all specimens. Test was performed on three randomly selected reinforcement bars and the mechanical properties of the reinforcement bar as found as below Table 1. The modulus of elasticity and Poisson's ratio for steel was taken as $200 \mathrm{Gpa}$ and 0.3 resp.

\section{2) Concrete}

The concrete mix used for casting the beams was designed for the proportions (by weight) of 1:2.3:4.2 with a free water-cement ratio of 0.45 .

The average compressive strength of the concrete cubes after 28 days was observed to be $27 \mathrm{~N} / \mathrm{mm}^{2}$. The Youngs modulus and poisons ratio of concrete are taken as $25,980.76 \mathrm{~N} / \mathrm{mm}^{2} \& 0.15$ respectively.

\section{3) Specimen details}

The specimens as shown in Figure 1 have a cross-section of $150 \mathrm{~mm} \times 150 \mathrm{~mm}$ and span of $1000 \mathrm{~mm}$. The concrete cover was $20 \mathrm{~mm}$. and at bottom $2 \# 10 \mathrm{~mm}$ and at top $2 \# 8 \mathrm{~mm}$ with $6 \mathrm{~mm}$ stirrups along the shear span at $110 \mathrm{~mm} \mathrm{C/C}$ spacing were provided.

\section{Analytical Model}

As shown in Figure 2 the specimen was modeled as the three dimensional specimen as to relate the experimen-

Table 1. Material property discription.

\begin{tabular}{ccc}
\hline Sr. No & Description & Property \\
1. & Bar size (nominal) & $10 \mathrm{~mm}$ \\
2. & Area of bar & $75.79 \mathrm{~mm}^{2}$ \\
3. & Weight of bar & $0.595 \mathrm{~kg} / \mathrm{m}$ \\
4. & Maximum load & $82.92 \mathrm{KN}$ \\
5. & Ultimate stress & $567.68 \mathrm{~N} / \mathrm{mm}^{2}$ \\
\hline
\end{tabular}

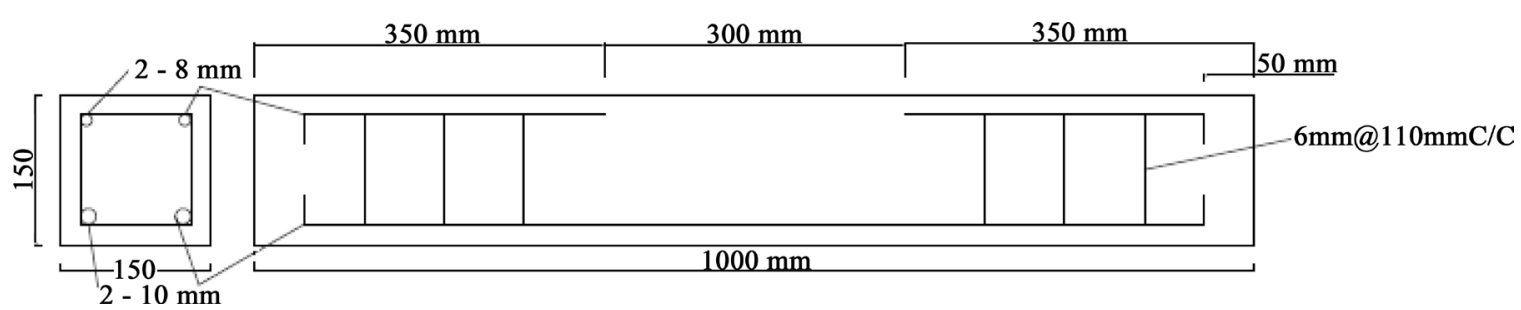

Figure 1. Specimen for test.

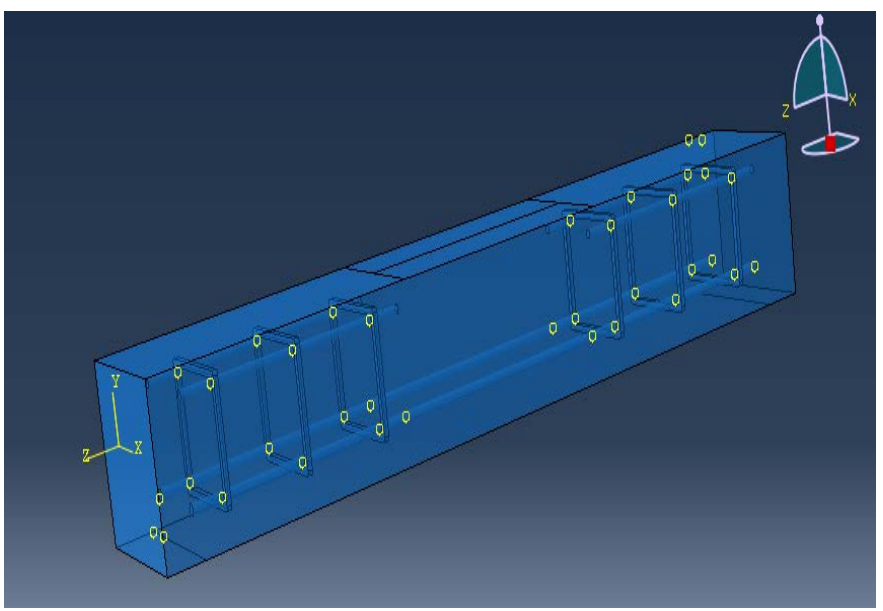

Figure 2. Modeling of beam. 
tal conditions. The specimens were modeled in ABAQUS software and deflection, stresses were analyzed. The loading and boundary conditions are given to the specimen as per mentioned in the literature [13]. For modeling of concrete 8 node brick element C3D8R is used while for modeling of steel and steel stirrups beam element is used with their respective material properties. Proper interaction between steel \& concrete is assured with the available options from software.

As given in the literature [13] only the part of the bottom steel was allowed to corrode as shown in Figure 3. The specimen in the ABAQUS was modeled as it is to ensure accurate results and also to ensure same conditions for comparison. The specimen for different percentage of corrosion $(0 \%, 2.5 \%, 5 \%, 7.5 \% \& 10 \%)$ is generated by providing a rust layer around the corroded bar as shown in Figure $4 \&$ Figure 5. In case of concrete part no changes are made for corroded specimen but in case of corroded steel, for different percentage of corrosion the mass loss of steel is calculated using Faraday's law [6] from the experimental data. The decreased in the diameter of steel for different percentage of corrosion is calculated and the same part is replaced by the rust in the modeled. A hollow cylindrical part is provided around the corroded region as a rust part.

\subsection{Development of FEA Model}

The non linear analysis is incorporated in the model by using the damaged plasticity approach provided in the ABAQUS software (SIMULIA 2013). ABAQUS also provides other options such as smeared crack concrete model, brittle crack concrete model for modeling of nonlinear analysis. The damaged plasticity model is used in the present study as this technique has the potential to represent complete inelastic behaviour of concrete both in

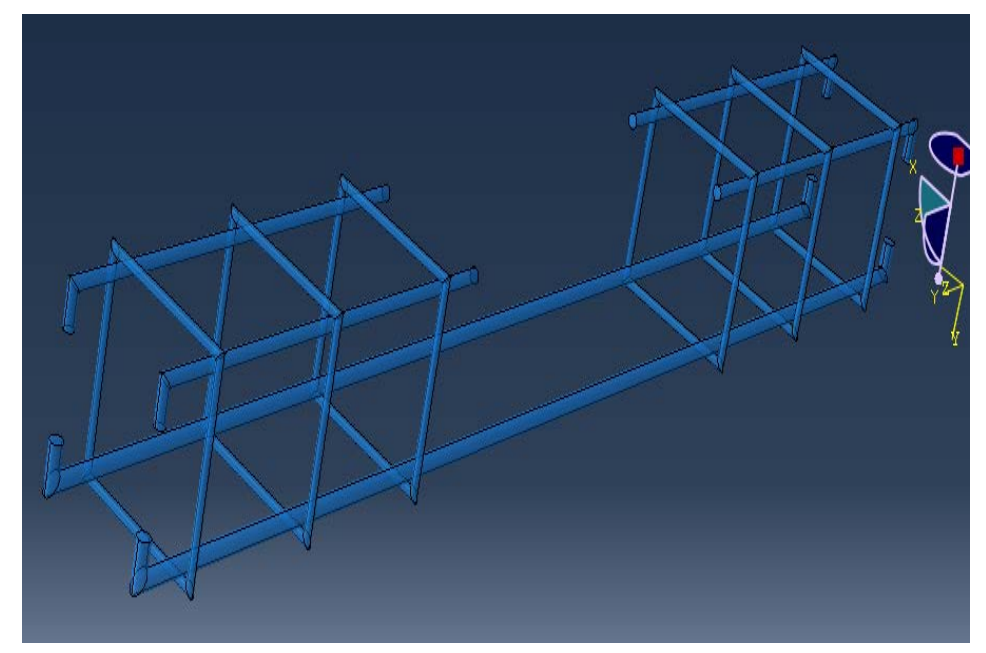

Figure 3. Modeling of steel.

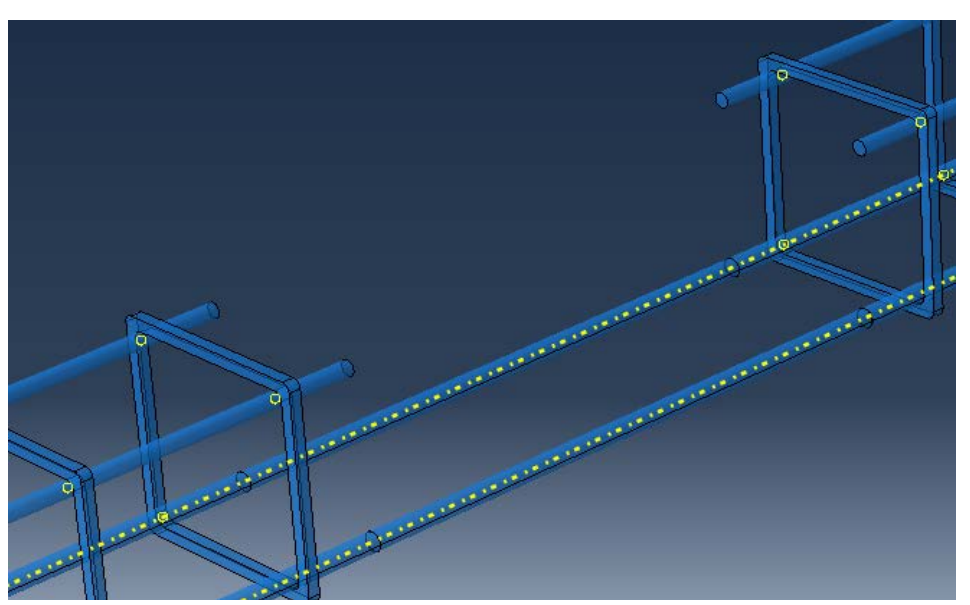

Figure 4. Corroded steel part. 


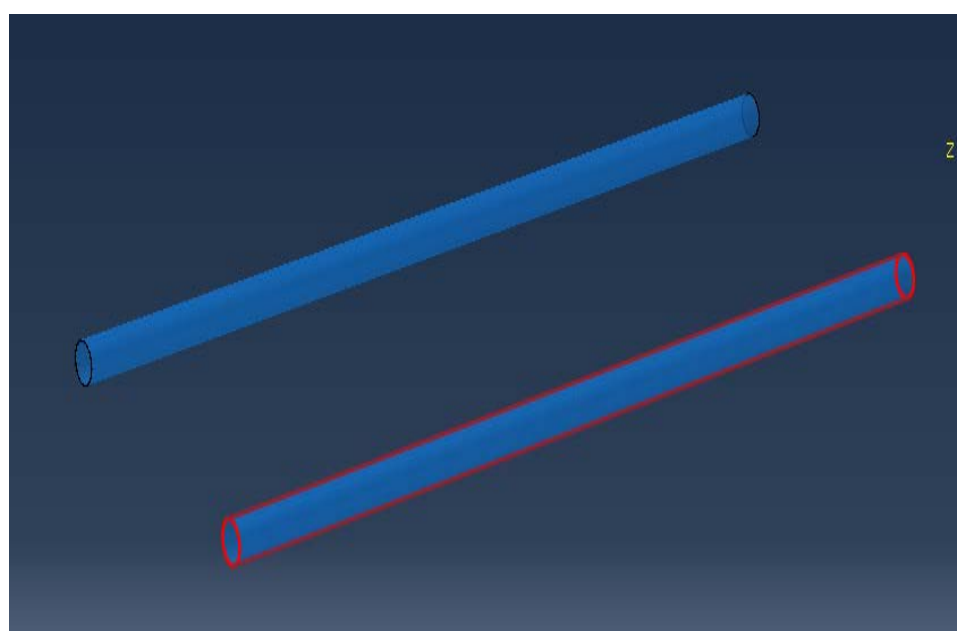

Figure 5. Rust part.

tension and compression with the damage characteristics. DPM model also enables to transfer the results from ABAQUS/standard \& ABAQUS/Explict and can be used between the two, which is further useful for any loading combinations including static and dynamic loading (Abaqus Analysis User Manual-Abaqus Version 6.12 [14]).

\subsection{Stress Strain Curve for Uniaxial Compression}

The stress-strain relation for a given concrete is obtained from the uniaxial compression tests results in the laboratory. The graph obtained from laboratory tests needs to transform the variables. To define the stress-strain relation of concrete in CDP, values of stress $\left(\sigma_{c}\right)$ inelastic strains $\left(\tilde{\varepsilon}_{c}^{\text {in }}\right)$ corresponds to stress values, and damaged properties $\left(d_{c}\right)$ need to calculate. Therefore the total strain is converted into inelastic strain as:

$$
\tilde{\varepsilon}_{c}^{i n}=\varepsilon_{c}-\varepsilon_{o c}^{e l}
$$

where, $\varepsilon_{o c}^{e l}=\frac{\sigma_{c}}{E_{0}} ; \quad \varepsilon_{o c}^{e l}=$ elastic strain corresponding to the damaged material and $E_{0}=$ total strain. The plastic strain values are calculated using equation,

$$
\tilde{\varepsilon}_{c}^{p l}=\tilde{\varepsilon}_{c}^{i n}-\frac{d_{c}}{\left(1-d_{c}\right)} \frac{\sigma_{c}}{E_{0}}
$$

Knowing the plastic strain and having determined the flow and failure surface area one can calculate stress $\sigma_{c}$ for uniaxial compression and its effective stress $\bar{\sigma}_{c}$.

$$
\begin{aligned}
& \sigma_{c}=\left(1-d_{c}\right) E_{0}\left(\varepsilon_{c}-\tilde{\varepsilon}_{c}^{p l}\right) \\
& \bar{\sigma}_{c}=\frac{\sigma_{c}}{\left(1-d_{c}\right)}=E_{0}\left(\varepsilon_{0}-\tilde{\varepsilon}_{c}^{p l}\right)
\end{aligned}
$$

Figure 6 and Figure 7 show tension stiffening model and terms for it as shown in Abaqus manual, 2012.

\subsection{Stress-Strain Curve for Uniaxial Tension}

The tensile stress-strain curve of concrete cannot be obtained directly from experiment therefore indirect methods such as splitting tests or beam bending test tend to be used. In order to simulate the complete tensile behavior of reinforced concrete in ABAQUS, a post failure stress-strain relationship for concrete subjected to tension (Figure 7) is used for tension stiffening strain softening and reinforcement interaction with concrete. To develop this model input required are Youngs modulus $\left(E_{0}\right)$ stress $\left(\sigma_{c}\right)$ cracking strain $\left(\tilde{\varepsilon}_{t}^{c k}\right)$ and damage parameter values $\left(d_{t}\right)$ for given grade of concrete. The cracking strain is calculated by deducting the elastic strain from the total strain as: 


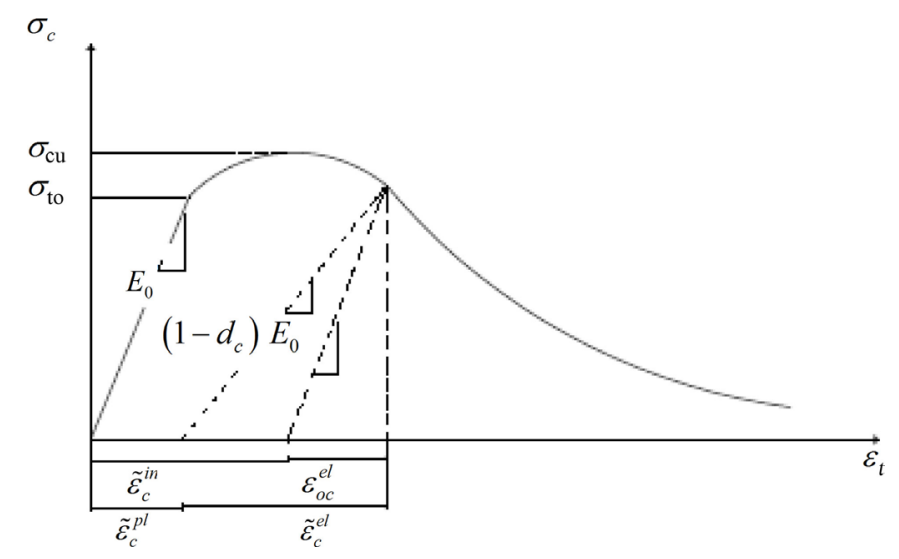

Figure 6. Tension stiffening model (abaqus manual, 2012).

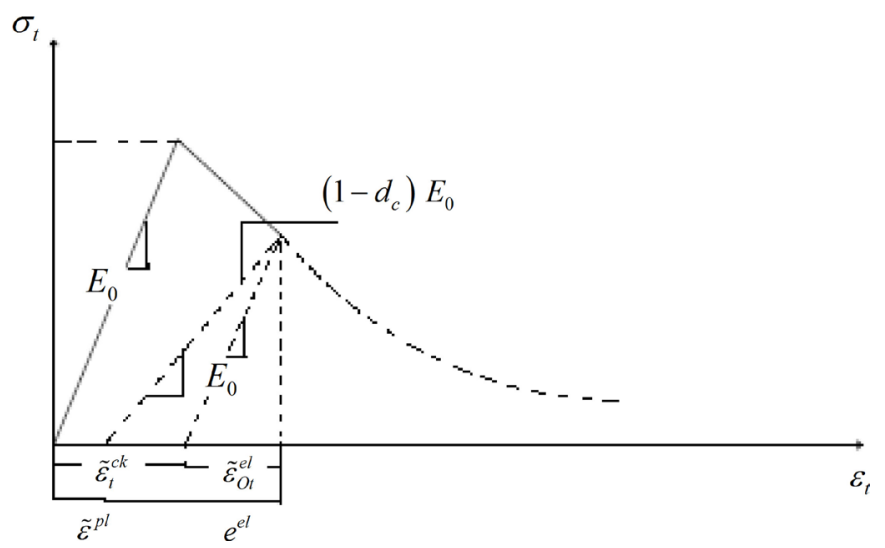

Figure 7. Terms for tension stiffening model (abaqus manual, 2012).

$$
\tilde{\varepsilon}_{t}^{c k}=\varepsilon_{t}-\tilde{\varepsilon}_{0 t}^{e l}
$$

where, $\varepsilon_{0 t}^{e l}=\frac{\sigma_{t}}{E_{c}}$.

Plastic strain $\quad \tilde{\varepsilon}_{t}^{c k}$ is calculated similarly as in the case of compression after defining degradation parameter $d_{t}$. In order to plot the stress-strain curve there needs to the form of the weakening function. According to user's manual, stress can be linearly reduced to zero, starting from the moment of reaching the tensile strength for the total strain ten times higher than at the moment reaching $\left(f_{c t m}\right)$. But to accurately describe this function the model needs to be calibrated with the results predicted for a specific analyzed case. The proper relation was proposed by Wang and Hsu as

$$
\begin{aligned}
& \sigma_{t}=E_{c} \varepsilon_{t} \quad \text { if } \varepsilon_{t} \leq \varepsilon_{c r} \\
& \sigma_{t}=f_{c m}\left(\frac{\varepsilon_{c r}}{\varepsilon_{t}}\right)^{0.4} \text { if } \varepsilon_{t}>\varepsilon_{c r}
\end{aligned}
$$

\section{Validation of FE Model by Experimental Results}

The FE analytical results indicate that as the percentage of corrosion increases the deflection of the beam increases. The analytical results are in good agreement with the experimental data used for the comparison [13]. In addition due to influence of assumed boundary conditions as discussed and the fact that finite element always gives stiffer response than reality, the FE analytical deformation were always greater than the actual measured ones. The deflection of beam for various percentage of corrosion is as shown in Figure 8. 
For $0 \%$ corrosion:

Deflection of beam for $70 \mathrm{KN}$ load

Deflection of beam for $2.5 \%$ corrosion, for loading of $70 \mathrm{KN}$ load

Deflection of beam for $5 \%$ corrosion, for loading of $70 \mathrm{KN}$ load

Deflection of beam for $10 \%$ corrosion, for loading of $70 \mathrm{KN}$ load
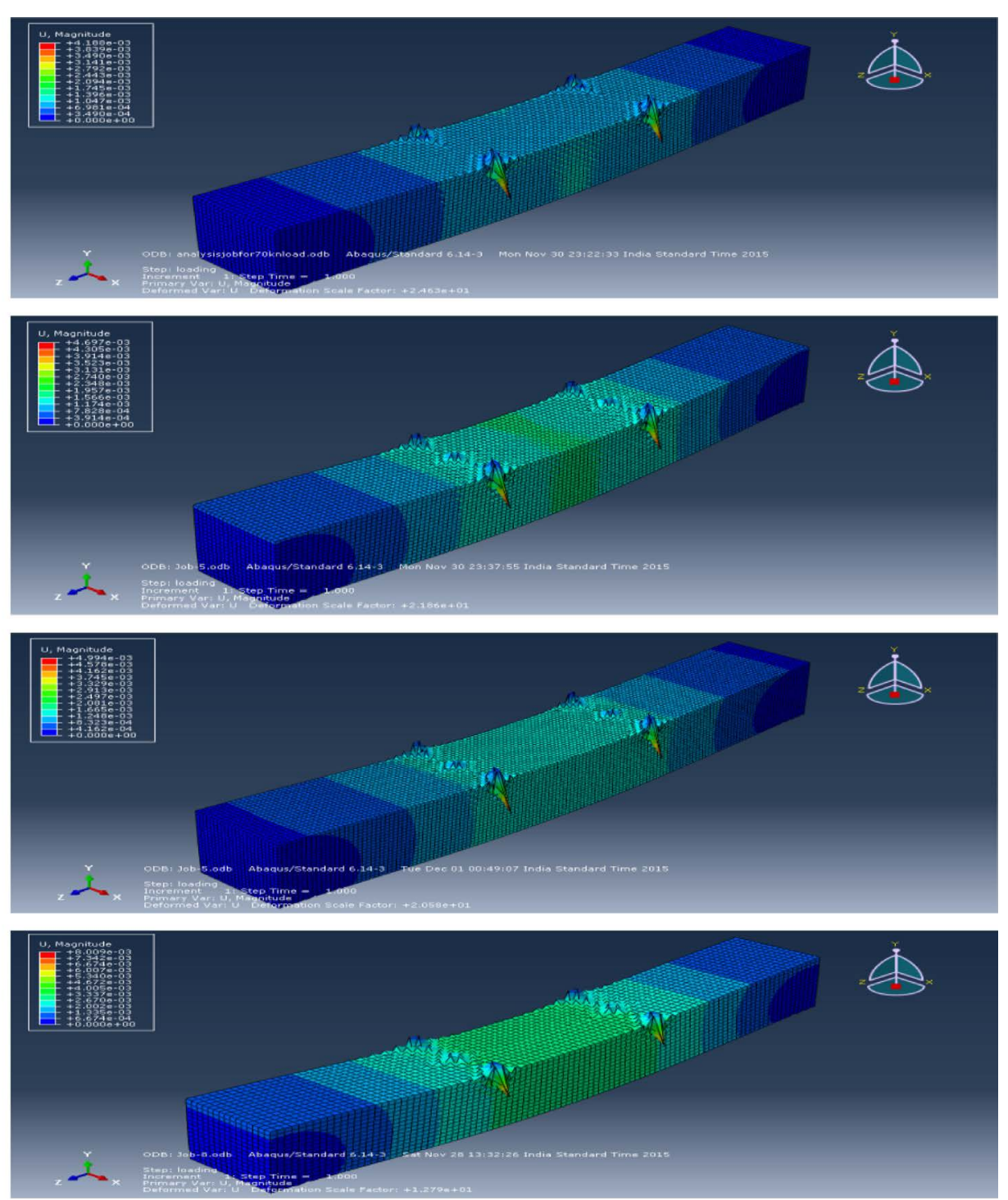

Figure 8. Deflection of beam for different \% of corrosion.

Table 2. Deflections (in $\mathrm{mm}$ ) for given percentage of corrosion and loading (kN).

\begin{tabular}{cccccccc}
\hline $\begin{array}{c}\text { Load } \\
\text { \% of corrosion }\end{array}$ & $20 \mathrm{kN}$ & $30 \mathrm{kN}$ & $40 \mathrm{kN}$ & $50 \mathrm{kN}$ & \multicolumn{2}{c}{$60 \mathrm{kN}$} & $70 \mathrm{kN}$ \\
\hline 0 & 1.612 & 2.418 & 3.223 & 4.029 & 4.835 & 5.641 \\
2.5 & 1.647 & 2.470 & 3.293 & 4.116 & 4.940 & 5.763 \\
5 & 1.695 & 2.970 & 3.893 & 4.743 & 5.210 & 5.940 \\
7.5 & 1.712 & 3.020 & 4.260 & 4.970 & 5.720 & 6.120 \\
10 & 2.288 & 3.433 & 4.577 & 5.721 & 6.865 & 8.009 \\
\hline
\end{tabular}

The Table 2 gives the mid span deflection for varying amount of corrosion percentage and for varying amount of loading. Form the analytical as well as experimental results it can been seen that corrosion up to about $1.5 \%$ does not affect the ultimate capacity while $4.5 \%$ of corrosion could reduce the ultimate load to an extent of $12 \%$. While Figure 9 shows the comparison of deflection for different percentage of corrosion and for varying loading conditions obtained from experimental results and analytically obtained from ABAQUS software. 


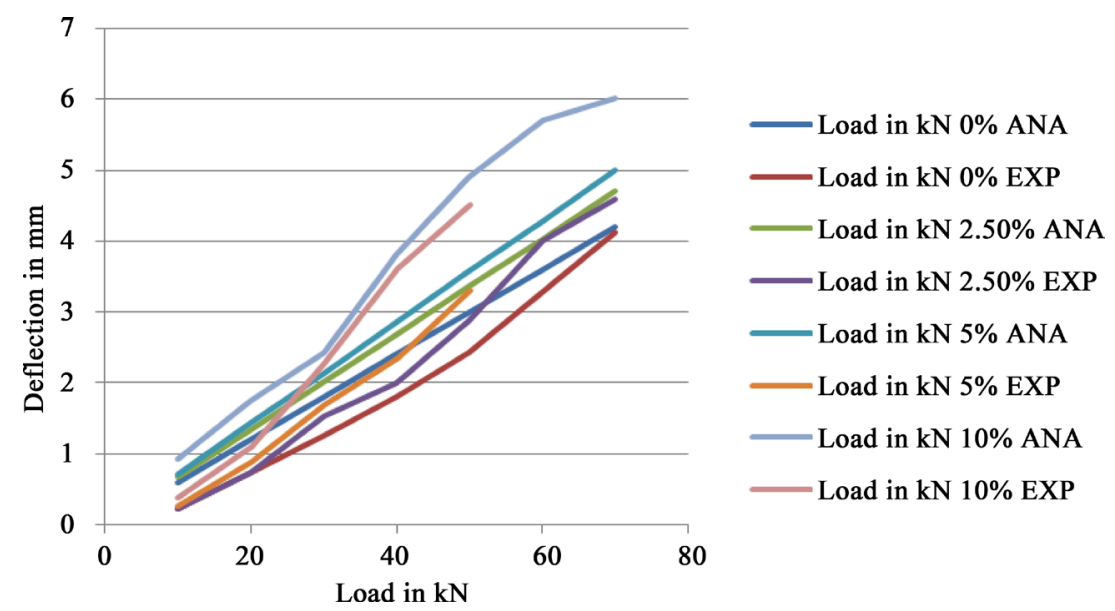

Figure 9. Comparison of deflection for different percentage of corrosion and for varying loading conditions.

\section{Conclusions}

Corrosion has a significant effect on the flexural strength of reinforced concrete beam.

Corrosion of steel rebar in an RC beam reduces effective cross-sectional steel area and creates local discontinuities of the steel surface.

From the results:

1) As the percentage of corrosion increases there is a decrease in ultimate flexural strength of RC beam.

2) There is an increase in mid span deflection of RC beam with the increase in corrosion percentage.

3) Corrosion up to about $1.5 \%$ does not affect the ultimate load carrying capacity while $4.5 \%$ of corrosion will reduce the ultimate load carrying capacity to an extent of $12 \%$.

\section{References}

[1] Hsu, L.S. and Hsu, C.-T.T. (1994) Complete Stress-Strain Behaviour of High-Strength Concrete under Compression. Magazine of Concrete Research, 46, 301-312. http://dx.doi.org/10.1680/macr.1994.46.169.301

[2] Nayal, R. and Rasheed, H.A. (2006) Tension Stiffening Model for Concrete Beams Reinforced with Steel and FRP Bars. Journal of Materials in Civil Engineering, 18, 831-841. http://dx.doi.org/10.1061/(ASCE)0899-1561(2006)18:6(831)

[3] Lubliner, J., Oliver, J., Oller, S. and Oñate, E. (1989) A Plastic-Damage Model for Concrete. International Journal of Solids and Structures, 25, 299-329. http://dx.doi.org/10.1016/0020-7683(89)90050-4

[4] Castel, A., Franfois, R. and Arliguie, G. (2000) Mechanical Behavior of Corroded Reinforced Concrete Beams. Materials and Structures, 33, 539-544. http://dx.doi.org/10.1007/BF02480533

[5] Azher, S.A. (2005) A Prediction Model for the Residual Flexural Strength of corroded Reinforced Concrete Beam. Ph.D. Thesis, King Fahd University of Petroleum and Minerals, Saudi Arabia.

[6] Ballim, Y. and Reid, J. (2003) Reinforcement Corrosion and the Deflection of RC Beams: An Experimental Critique of Current Test Methods. Cement and Concrete Composites, 25, 625-632. http://dx.doi.org/10.1016/S0958-9465(02)00076-8

[7] Broomfield, J.P. (1997) Corrosion of Steel in Concrete: Understand Investigation and Repair. E \& FN Spon, London. http://dx.doi.org/10.4324/9780203414606

[8] Cabrera, J.G. and Ghoddoussi, P. (2001) The Effect of Reinforcement Corrosion on the Strength of the Steel/Concrete Bond. International Conference on Bond in Concrete, 11-24.

[9] Li, C.Q. and Zheng, J.J. (2005) Propagation of Reinforcement Corrosion in Concrete and Its Effects on Structural Deterioration. Magazine of Concrete Research, .57, 261-271. http://dx.doi.org/10.1680/macr.2005.57.5.261

[10] Coronelli, D. and Gambarova, P. (2004) Structural Assessment of Corroded Reinforced Concrete Beams: Modeling Guidelines. Journal of Structural Engineering, 130, 1214-1224. http://dx.doi.org/10.1061/(ASCE)0733-9445(2004)130:8(1214)

[11] Eyre, J.R. and Nokhasteh, M.A. (1992) Strength Assessment of Corrosion Damaged Reinforced Slabs and Beams. Institution Civil Engineers, Structures and Buildings, 94, 197-203. http://dx.doi.org/10.1680/istbu.1992.18788 
[12] O’Flaherty, F.J., Mangat, P.S., Lambert, P. and Browne, E.H. (2008) Effect of Under-Reinforcement on the Flexural Strength of Corroded Beams. Materials and Structures, 41, 311-321. http://dx.doi.org/10.1617/s11527-007-9241-1

[13] Patil, A.N. (2011) Residual Flexural Strength of RC Beams Subjected to Corrosion. M.Tech Thesis, College of Engineering Pune.

[14] Abaqus Analysis User Manual-Abaqus Version 6.12 (2012). 